\title{
Comparing short-term outcomes after totally laparoscopic distal gastrectomy and laparoscopy-assisted distal gastrectomy with Billroth I anastomosis: early experience of a single institution
}

\author{
Inhyuck Lee, Kwang Hee Kim, Sang Hyuk Seo, Min Sung An, HyungJoo Baik, Yo Han Park, Sang Hyun Kang, Sang Hoon Oh \\ Department of Surgery, Inje University Busan Paik Hospital, Busan, Korea
}

Purpose: To determine the safety and feasibility of totally laparoscopic distal gastrectomy (TLDG) with modified delta-shaped anastomosis, we compared the short-term outcomes of TLDG to those of laparoscopy-assisted distal gastrectomy (LADG) with Billroth I anastomosis.

Methods: We analyzed the characteristics of 85 patients with gastric cancer who underwent laparoscopic distal gastrectomy with Billroth I anastomosis between January 2013 and December 2018. After propensity score matching, each group had 35 patients.

Results: Of these 85 patients, 44 underwent TLDG and 41 underwent LADG. Propensity score matching was performed with three covariates (age, underlying disease, and hypertension), and 35 patients from each group were matched 1:1. After matching, the TLDG group was older than the LADG group (64.5 \pm 10.6 years vs. $56.3 \pm 11.2$ years, $p=0.003)$ and had more patients with hypertension $(57.1 \%$ vs. $22.9 \%, p=0.003)$. Tumors were larger in the TLDG group than in the LADG group $(23.4 \pm 16.2 \mathrm{~mm}$ vs. $16.0 \pm 7.9 \mathrm{~mm}, p=$ 0.018). A greater proportion of patients had fever in the TLDG group than the LADG group $(42.9 \%$ vs. $20.0 \%, p=0.039$ ), and C-reactive protein from postoperative days 3 to 6 was greater in the TLDG group $(11.4 \pm 5.7 \mathrm{mg} / \mathrm{dL}$ vs. $7.0 \pm 5.0 \mathrm{mg} / \mathrm{dL}, p=0.001)$.

Conclusion: Although our data represent only our early experience performing TLDG with modified deltashaped anastomosis, this procedure is relatively safe and feasible. Nevertheless, compared to LADG, which is the conventional method, the operative time for TLDG was longer. Surgeons must also watch out for anastomotic complications.

Keywords: Gastroenterostomy, Laparoscopy, Stomach neoplasms

This is an Open Access article distributed under the terms of the Creative Commons Attribution Non-Commercial License (http:// creativecommons.org/licenses/by-nc/4.0/) which permits unrestricted non-commercial use, distribution, and reproduction in any medium, provided the original work is properly cited.
Received September 3, 2020

Revised 1st October 26, 2020 2nd November 19, 2020 3rd November 20, 2020 4th November 23, 2020

Accepted November 24, 2020

Corresponding author

Sang Hyuk Seo

Department of Surgery, Inje University Busan Paik Hospital, Bokjiro 75,

Busanjin-gu, Busan 47392, Korea

Tel: +82-51-890-6948

Fax: +82-51-898-9427

E-mail: sshgs@paik.ac.kr

ORCID

https://orcid.org/0000-0002-7264-1339

Inhyuck Lee and Kwang Hee Kim are the co-first author of this work. Inhyuck Lee, Kwang Hee Kim, and Sang Hyuk Seo contributed equally to this work.

Copyright $@ 2021$ The Journal of Minimally Invasive Surgery. All rights reserved.

\section{INTRODUCTION}

Gastric cancer is the fifth most common cancer worldwide, and its incidence is high in East Asia [1,2]. Moreover, the proportion of patients with early gastric cancer is increasing due to expanding interest in health care, improvements in diet, advancements in endoscopy, and increased range of health screening examinations $[3,4]$.
Introduced in the early 1990s, laparoscopic gastrectomy is considered the standard treatment of early gastric cancer. The number of laparoscopic gastrectomy procedures is increasing with the increasing prevalence of early gastric cancer $[5,6]$. Furthermore, laparoscopic gastrectomy is being used to treat advanced gastric cancer by surgeons who perform laparoscopic D2 lymph node dissection [7-9].

Typically, laparoscopic distal gastrectomy requires extracorpo- 
real anastomosis via mini-laparotomy of the upper abdomen; this technique is known as laparoscopy-assisted distal gastrectomy (LADG) [10]. Totally laparoscopic distal gastrectomy (TLDG) was developed in the early 2000s and uses various techniques to achieve intracorporeal anastomosis. Without mini-laparotomy of the upper abdomen, patients experience less pain, fewer wound complications, and may experience cosmetic benefits [11-14].

Billroth I anastomosis, which is a commonly used reconstruction method in distal gastrectomy, has some advantages over other reconstruction methods, including preserved duodenal passage, lower incidence of postoperative cholecystitis and cholelithiasis, use of a single anastomosis, and the possibility of endoscopic approach to the ampulla of Vater $[15,16]$. Therefore, when possible, surgeons at our institution perform Billroth I anastomosis in patients who require distal gastrectomy. At our institution, we began performing LADG with Billroth I anastomosis in the early 2000s; since 2015, we have used TLDG with modified deltashaped anastomosis.

In this study, we investigated the short-term outcomes of our early experience performing TLDG with modified delta-shaped anastomosis at our institution, and we compared these outcomes to those of LADG with Billroth I anastomosis to analyze the safety and feasibility of TLDG.

\section{MATERIALS AND METHODS}

\section{Patients}

We enrolled all patients with gastric cancer who underwent laparoscopic distal gastrectomy with Billroth I anastomosis between January 2013 and December 2018 at Inje University Busan Paik Hospital. These operations were performed by one of two upper gastrointestinal tract surgeons. Between 2013 and 2015, patients with early gastric cancer as determined via preoperative esophagogastroduodenoscopy and abdominopelvic computed tomography underwent LADG. All tumors were marked with a clip during preoperative esophagogastroduodenoscopy, and the surgeon manually located this clip during upper mini-laparotomy. The resection margin was identified, and Billroth I anastomosis was performed when possible. Since October 2015, surgeons have identified this preoperative clip with intraoperative abdominal radiography. TLDG with modified delta-shaped anastomosis was performed when Billroth I anastomosis was possible. Moreover, since 2016, patients with advanced gastric cancer without metastasis or direct invasion to adjacent organs were also considered for laparoscopic surgery. For this study, we prospectively enrolled patients and retrospectively reviewed their medical records.

\section{Surgical procedures and techniques}

We performed all laparoscopic distal gastrectomy and lymph node dissection procedures according to the 2014 treatment guidelines of the Japanese Gastric Cancer Association (version 4) [17]. We used the conventional five-port method. Partial omentectomy and $\mathrm{D} 1+$ lymph node dissection were routinely performed; however, when necessary, total omentectomy and D2 lymph node dissection were performed instead. The proximal duodenum was divided with a linear stapler. After gastrectomy and reconstruction of the gastrointestinal tract, hemostasis was achieved and a surgical drain was inserted.

\section{Totally laparoscopic distal gastrectomy}

After duodenal division and determination of the resection margin, the stomach was resected with two linear staplers. If the appropriate resection margin was unclear, intraoperative supine abdominal radiography was used to confirm the location for endoscopic clipping. Entry holes were made at both the ventral edge of the duodenum and the greater curvature of the stomach. Gastroduodenostomy was performed by inserting a linear stapler into both entry holes, and the entry holes and stapled lines of the duodenal stump were resected with two additional linear staplers; this procedure is called modified delta-shaped anastomosis [18].

\section{Laparoscopy-assisted distal gastrectomy}

After duodenal division, a 6-cm incision was made in the upper abdomen. Then, the anvil was manually inserted extracorporeally into the duodenal stump, which was closed with purse-string sutures. The gastric lesion was detected, and the surgeon determined the resection margin by palpation or visual confirmation of the previously inserted endoscopic clip. Gastrotomy was performed on the distal side of the resection margin, and a circular stapler was inserted. Finally, gastroduodenostomy was performed at the posterior wall of the remnant stomach, and resection at the distal side of the resection margin was performed with a linear stapler.

\section{Clinical outcomes}

We retrospectively reviewed patient medical records, including the operative, pathologic, and nursing records. The pathologic tumor, node, metastasis (TNM) stage was recorded according to the seventh edition of the Cancer Staging Manual published by the American Joint Committee on Cancer [19]. The American Society of Anesthesiologists physical status (ASA PS) classification was determined by the anesthesiologists for each operation [20]. Pain medications, including tramadol, paracetamol, and nonsteroidal anti-inflammatory drugs, were recorded only when the 
patient requested additional doses by injection. Fever was defined as a body temperature of $38.0^{\circ} \mathrm{C}$ or greater. All laboratory findings, which included hemoglobin and C-reactive protein (CRP) levels and white blood cell (WBC) count, were collected from postoperative days 3 to 6 , regardless of whether tests were performed. If the laboratory tests were performed more than once per day, the results of the earliest tests were recorded. Change in hemoglobin was defined as the difference between the preoperative hemoglobin level and the mean value of postoperative days 3 to 6 . The Clavien-Dindo (CD) classification was calculated according to the classifications for surgical complications by the Annals of Surgery (August 2004) [21]. A CD classification of III or greater was used to define the presence of major complications. Anastomotic complications included anastomotic leakage, stricture, delayed gastric emptying, and intraabdominal abscess. Readmission was defined as hospitalization within 30 days of the initial discharge date.

\section{Statistical analyses}

We used the two-sample $t$ test to analyze continuous variables and the Pearson chi-square or Fisher exact test to analyze categorical variables. A $p$ value of $<0.05$ was considered statistically significant. Propensity score matching with nearest neighbor matching was performed, and we used age, underlying disease, and hypertension as covariates. We used R version 4.0.3 ( $\mathrm{R}$ Foundation for Statistical Computing, Vienna, Austria) and IBM SPSS version 25 (IBM Corp., Armonk, NY, USA) to perform our analyses.

Table 1. Clinical characteristics of patients

\begin{tabular}{|c|c|c|c|c|c|c|c|c|}
\hline \multirow[b]{2}{*}{ Characteristic } & \multicolumn{4}{|c|}{ Total population } & \multicolumn{4}{|c|}{ Propensity matched population } \\
\hline & $\begin{array}{c}\text { TLDG } \\
(n=44)\end{array}$ & $\begin{array}{c}\text { LADG } \\
(n=41)\end{array}$ & $p$ value & $\begin{array}{c}\text { Standardized } \\
\text { difference }^{\text {a) }}\end{array}$ & $\begin{array}{c}\text { TLDG } \\
(n=35)\end{array}$ & $\begin{array}{l}\text { LADG } \\
(n=35)\end{array}$ & $p$ value & $\begin{array}{c}\text { Standardized } \\
\text { difference }^{a}\end{array}$ \\
\hline Age (yr) & $63.6 \pm 11.6$ & $57.4 \pm 11.5$ & 0.015 & 4.6728 & $64.5 \pm 10.6$ & $56.3 \pm 11.2$ & 0.003 & -2.5235 \\
\hline Sex & & & 0.165 & & & & 0.039 & \\
\hline Male & $33(75.0)$ & $24(58.5)$ & & & $28(80.0)$ & $20(57.1)$ & & \\
\hline Female & $11(25.0)$ & $17(41.5)$ & & & $7(20.0)$ & $15(42.9)$ & & \\
\hline Body mass index $\left(\mathrm{kg} / \mathrm{m}^{2}\right)$ & $24.0 \pm 3.1$ & $23.4 \pm 2.5$ & 0.287 & & $24.1 \pm 2.3$ & $23.3 \pm 2.6$ & 0.186 & \\
\hline ASA & & & 0.100 & & & & 0.025 & \\
\hline I & $10(22.7)$ & $18(43.9)$ & & & $7(20.0)$ & $16(45.7)$ & & \\
\hline$\|$ & $26(59.1)$ & $19(46.3)$ & & & $20(57.1)$ & $17(48.6)$ & & \\
\hline || & $8(18.2)$ & $4(9.8)$ & & & $8(22.9)$ & $2(5.7)$ & & \\
\hline Underlying disease & & & 0.083 & 0.4022 & & & 0.092 & 0.6995 \\
\hline No & $15(34.1)$ & $22(53.7)$ & & & $12(34.3)$ & $19(54.3)$ & & \\
\hline Yes & $29(65.9)$ & $19(46.3)$ & & & $23(65.7)$ & $16(45.7)$ & & \\
\hline Hypertension & $25(56.8)$ & $10(24.4)$ & 0.004 & 0.4111 & $20(57.1)$ & $8(22.9)$ & 0.003 & 0.7471 \\
\hline Diabetes mellitus & $11(25.0)$ & $5(12.2)$ & 0.169 & & $9(25.7)$ & $4(11.4)$ & 0.124 & \\
\hline Obstructive lung disease & $4(9.1)$ & $2(4.9)$ & 0.677 & & $3(8.6)$ & $1(2.9)$ & 0.614 & \\
\hline Ischemic heart disease & $1(2.3)$ & $3(7.3)$ & 0.349 & & $1(2.9)$ & $0(0.0)$ & $>0.999$ & \\
\hline Arrhythmia & $2(4.5)$ & $0(0.0)$ & 0.495 & & $2(5.7)$ & $0(0.0)$ & 0.493 & \\
\hline Chronic kidney disease & $1(2.3)$ & $0(0.0)$ & $>0.999$ & & $1(2.9)$ & $0(0.0)$ & $>0.999$ & \\
\hline Liver cirrhosis & $1(2.3)$ & $1(2.4)$ & $>0.999$ & & $1(2.9)$ & $1(2.9)$ & $>0.999$ & \\
\hline Previous operation history & $9(20.5)$ & $8(19.5)$ & $>0.999$ & & $7(20.0)$ & $7(20.0)$ & $>0.999$ & \\
\hline
\end{tabular}

Values are presented as mean \pm standard deviation or number (\%).

TLDG, totally laparoscopic distal gastrectomy; LADG, laparoscopy-assisted distal gastrectomy; ASA, American Society of Anesthesiologists physical status classification.

a) In general, if the standardized difference is less than 0.1 , the difference in the covariate can be neglected. 


\section{RESULTS}

We included 85 patients who underwent laparoscopic distal gastrectomy; 44 patients underwent TLDG and 41 underwent LADG. Propensity score matching was performed with three covariates (age, underlying disease, and hypertension), and 35 patients from each group were matched 1:1.

\section{Clinical characteristics}

Table 1 lists the clinical characteristics of the enrolled patients. After matching, the TLDG group included 28 males (80.0\%) and seven females (20.0\%), with a mean age of $64.5 \pm 10.6$ years. The LADG group included 20 males (57.1\%) and 15 females (42.9\%), with a mean age of $56.3 \pm 11.2$ years. The groups were statistically different in terms of sex $(p=0.039)$, and the mean age was significantly greater in the TLDG group $(p=0.003)$. Mean body

Table 2. Pathologic outcomes

\begin{tabular}{|c|c|c|c|c|c|c|}
\hline \multirow{2}{*}{ Variable } & \multicolumn{3}{|c|}{ Total population } & \multicolumn{3}{|c|}{ Propensity matched population } \\
\hline & $\operatorname{TLDG}(n=44)$ & LADG $(n=41)$ & $p$ value & $\operatorname{TLDG}(\mathrm{n}=35)$ & LADG $(n=35)$ & $p$ value \\
\hline Tumor size (mm) & $23.3 \pm 18.7$ & $16.5 \pm 8.1$ & 0.040 & $23.4 \pm 16.2$ & $16.0 \pm 7.9$ & 0.018 \\
\hline Harvested lymph nodes & $32.6 \pm 9.2$ & $34.5 \pm 11.7$ & 0.393 & $32.1 \pm 9.0$ & $35.6 \pm 12.4$ & 0.166 \\
\hline T stage & & & 0.072 & & & 0.235 \\
\hline $\mathrm{T} 1$ & $37(84.1)$ & $38(92.7)$ & & $29(82.9)$ & $33(94.3)$ & \\
\hline T2 & $2(4.5)$ & $2(4.9)$ & & $2(5.7)$ & $2(5.7)$ & \\
\hline T3 & $2(4.5)$ & $0(0)$ & & $2(5.7)$ & $0(0)$ & \\
\hline $\mathrm{T} 4$ & $2(4.5)$ & $0(0)$ & & $2(5.7)$ & $0(0)$ & \\
\hline N stage & & & 0.228 & & & 0.203 \\
\hline NO & $36(81.8)$ & $38(92.7)$ & & $28(80.0)$ & $33(94.3)$ & \\
\hline N1 & $3(6.8)$ & $1(2.4)$ & & $3(8.6)$ & $0(0)$ & \\
\hline N2 & $3(6.8)$ & $2(4.9)$ & & $3(8.6)$ & $2(5.7)$ & \\
\hline N3 & $1(2.3)$ & $0(0)$ & & $1(2.9)$ & $0(0)$ & \\
\hline Stage & & & 0.096 & & & 0.177 \\
\hline I & $38(86.4)$ & $39(95.1)$ & & $29(82.9)$ & $33(94.3)$ & \\
\hline$\|$ & $3(6.8)$ & $2(4.9)$ & & $3(8.6)$ & $2(5.7)$ & \\
\hline III & $3(6.8)$ & $0(0)$ & & $3(8.6)$ & $0(0)$ & \\
\hline Cell differentiation & & & 0.254 & & & 0.212 \\
\hline Differentiated & $30(68.2)$ & $23(56.1)$ & & $25(71.4)$ & $20(57.1)$ & \\
\hline Undifferentiated & $12(27.3)$ & $16(39.0)$ & & $10(28.6)$ & $15(42.9)$ & \\
\hline Lauren classification & & & 0.704 & & & 0.394 \\
\hline Intestinal & $30(68.2)$ & $22(53.7)$ & & $25(71.4)$ & $21(60.0)$ & \\
\hline Diffuse & $8(18.2)$ & $12(29.3)$ & & $7(20.0)$ & $12(34.3)$ & \\
\hline Mixed & $4(9.1)$ & $2(4.9)$ & & $3(8.6)$ & $2(5.7)$ & \\
\hline$(-)$ & $1(2.3)$ & $1(2.4)$ & & $0(0)$ & $0(0)$ & \\
\hline \multicolumn{7}{|l|}{ Invasion } \\
\hline Lymphatic & $8(18.2)$ & $3(7.3)$ & 0.203 & $8(22.9)$ & $3(8.6)$ & 0.101 \\
\hline Venous & $1(2.3)$ & $0(0)$ & $>0.999$ & $1(2.9)$ & $0(0)$ & $>0.999$ \\
\hline Neural & $5(11.4)$ & $1(2.4)$ & 0.206 & $5(14.3)$ & $1(2.9)$ & 0.198 \\
\hline
\end{tabular}

Values are presented as mean \pm standard deviation or number $(\%)$.

TLDG, totally laparoscopic distal gastrectomy; LADG, laparoscopy-assisted distal gastrectomy. 
mass index was similar between groups $\left(24.1 \pm 2.3 \mathrm{~kg} / \mathrm{m}^{2}\right.$ for the TLDG group vs. $23.3 \pm 2.6 \mathrm{~kg} / \mathrm{m}^{2}$ for the LADG group, $p=0.186$ ). Preoperative ASA PS classification was significantly higher in the TLDG groups (in the TLDG group, seven patients [20.0\%] had ASA I, 20 [57.1\%] had ASA II, and eight [22.9\%] had ASA III; in the LADG group, 16 patients [45.7\%] had ASA I, 17 [48.6\%] had ASA II, and two [5.7\%] had ASA III; $p=0.025$ ).

More patients who underwent TLDG had underlying disease than those who underwent LADG (23 patients [65.7\%] vs. 16 [45.7\%], respectively), but this difference was not statistically significant $(p=0.092)$. Patients in the TLDG group had hypertension (20 patients [57.1\%]), diabetes mellitus (nine [25.7\%]), obstructive lung disease (three [8.6\%]), ischemic heart disease (one [2.9\%]), arrhythmia (two [5.7\%]), chronic kidney disease (one [2.9\%]), and liver cirrhosis (one [2.9\%]). Patients in the LADG group had hy- pertension (eight patients [22.9\%]), diabetes mellitus (four [11.4\%]), obstructive lung disease (one [2.9\%]), and liver cirrhosis (one [2.9\%]), but no patient had ischemic heart disease, arrhythmia, or chronic kidney disease. Only the prevalence of hypertension was significantly different between groups ( $p=0.003$ ). Similar numbers of patients had a history of abdominal surgery (seven patients [20.0\%] in the TLDG group vs. seven [20.0\%] in the LADG group, $p>0.999$ ).

\section{Pathologic outcomes}

Table 2 lists the pathologic outcomes. After matching, the mean \pm standard deviation of tumor size was $23.4 \pm 16.2 \mathrm{~mm}$ in the TLDG group and $16.0 \pm 7.9 \mathrm{~mm}$ in the LADG group $(p=0.018)$. The number of harvested lymph nodes was $32.1 \pm 9.0$ in the

Table 3. Surgical outcomes

\begin{tabular}{|c|c|c|c|c|c|c|}
\hline \multirow{2}{*}{ Variable } & \multicolumn{3}{|c|}{ Total population } & \multicolumn{3}{|c|}{ Propensity matched population } \\
\hline & $\operatorname{TLDG}(n=44)$ & $\operatorname{LADG}(n=41)$ & $p$ value & $\operatorname{TLDG}(n=35)$ & $\operatorname{LADG}(n=35)$ & $p$ value \\
\hline Blood loss (mL) & $106.6 \pm 102.5$ & $145.6 \pm 117.7$ & 0.106 & $94.9 \pm 65.1$ & $145.4 \pm 116.9$ & 0.029 \\
\hline Operation time (min) & $215.8 \pm 39.6$ & $167.5 \pm 32.0$ & $<0.001$ & $211.3 \pm 30.3$ & $168.0 \pm 33.8$ & $<0.001$ \\
\hline Full liquid diet started (day) & $4.4 \pm 0.9$ & $5.1 \pm 1.2$ & 0.007 & $4.6 \pm 1.0$ & $5.1 \pm 1.2$ & 0.053 \\
\hline Gas first passed (day) & $3.6 \pm 1.5$ & $3.8 \pm 1.6$ & 0.718 & $3.8 \pm 1.6$ & $3.8 \pm 1.6$ & 0.94 \\
\hline Length of hospital stay (day) & $10.1 \pm 7.4$ & $10.0 \pm 9.5$ & 0.962 & $10.6 \pm 8.2$ & $8.6 \pm 1.8$ & 0.159 \\
\hline Readmission within 30 days & $3(6.8)$ & $1(2.4)$ & 0.617 & $3(8.6)$ & $0(0)$ & 0.239 \\
\hline Additional use of pain medications & $2.4 \pm 2.4$ & $3.4 \pm 3.0$ & 0.502 & $2.4 \pm 2.4$ & $3.3 \pm 2.8$ & 0.164 \\
\hline Body temperature, $\geq 38.0^{\circ} \mathrm{C}$ & & & 0.081 & & & 0.039 \\
\hline No & $26(59.1)$ & $32(78.0)$ & & $20(57.1)$ & $28(80.0)$ & \\
\hline Yes & $18(40.9)$ & $9(22.0)$ & & $15(42.9)$ & $7(20.0)$ & \\
\hline Change in hemoglobin & $2.6 \pm 1.3$ & $2.5 \pm 1.1$ & 0.818 & $2.5 \pm 1.3$ & $2.6 \pm 1.2$ & 0.796 \\
\hline WBC (cell/nL), POD 3-6 & $7,769.0 \pm 2,386.8$ & $7,725.1 \pm 2,400.7$ & 0.933 & $7,883.5 \pm 2,513.6$ & $7,371.9 \pm 2,059.6$ & 0.355 \\
\hline CRP (mg/dL), POD 3-6 & $11.3 \pm 6.5$ & $7.48 \pm 5.7$ & 0.005 & $11.4 \pm 5.7$ & $7.0 \pm 5.0$ & 0.001 \\
\hline CD classification & & & 0.212 & & & 0.325 \\
\hline 0 & $20(45.5)$ & $23(56.1)$ & & $16(45.7)$ & $22(62.9)$ & \\
\hline । & $6(13.6)$ & $5(12.2)$ & & $5(14.3)$ & $5(14.3)$ & \\
\hline$\|$ & $14(31.8)$ & $11(26.8)$ & & $11(31.4)$ & $8(22.9)$ & \\
\hline III & $2(4.5)$ & $2(4.9)$ & & $2(5.7)$ & $0(0)$ & \\
\hline IV & $1(2.3)$ & $0(0)$ & & $1(2.9)$ & $0(0)$ & \\
\hline V & $1(2.3)$ & $0(0)$ & & $0(0)$ & $0(0)$ & \\
\hline Major complication" & $4(9.1)$ & $2(4.9)$ & 0.677 & $3(8.6)$ & $0(0)$ & 0.239 \\
\hline
\end{tabular}

Values are presented as mean \pm standard deviation or number (\%).

TLDG, totally laparoscopic distal gastrectomy; LADG, laparoscopy-assisted distal gastrectomy; WBC, white blood cell count; POD, postoperative day; CRP, C-reactive protein; CD, Clavien-Dindo.

${ }^{\text {a) }} \mathrm{CD}$ classification $>\|$. 
Table 4. Details of anastomotic complications

\begin{tabular}{|c|c|c|c|c|c|c|}
\hline \multirow{2}{*}{ Variable } & \multicolumn{3}{|c|}{ Total population } & \multicolumn{3}{|c|}{ Propensity score matching } \\
\hline & $\operatorname{TLDG}(n=44)$ & $\operatorname{LADG}(n=41)$ & $p$ value & $\operatorname{TLDG}(\mathrm{n}=35)$ & $\operatorname{LADG}(n=35)$ & $p$ value \\
\hline Anastomotic complication & $5(11.4)$ & $2(4.9)$ & 0.435 & $5(14.3)$ & $0(0.0)$ & 0.054 \\
\hline Delayed gastric emptying & 1 & 0 & & 1 & 0 & \\
\hline Anastomotic stricture & 1 & 1 & & 1 & 0 & \\
\hline Anastomotic leakage & 1 & 0 & & 1 & 0 & \\
\hline Intraabdominal abscess & 2 & 1 & & 2 & 0 & \\
\hline
\end{tabular}

Values are presented as number (\%) or number only.

TLDG, totally laparoscopic distal gastrectomy; LADG, laparoscopy-assisted distal gastrectomy.

TLDG group and $35.6 \pm 12.4$ in the LADG group ( $p=0.166$ ). In the TLDG group, 29 patients $(82.9 \%)$ had T1 stage disease, two (5.7\%) had T2, two (5.7\%) had T3, and two (5.7\%) had T4. In the LADG group, 33 patients (94.3\%) had T1 stage disease, two (5.7\%) had $\mathrm{T} 2$, and no one had $\mathrm{T} 3$ or T4. The groups were similar in terms of T stage ( $p=0.235)$. The TLDG group had more patients with advanced-stage gastric cancer (29 patients [82.9\%] had stage I, three [8.6\%] had stage II, and one [8.6\%] had stage III) than the LADG group (33 [94.3\%] had stage I, two [5.7\%] had stage II, and no one had stage III), but the groups were statistically similar ( $p=$ 0.177). Groups were similar in terms of cell differentiation, Lauren classification, and lymphatic, venous, and neural invasion.

\section{Surgical and clinical outcomes}

Table 3 shows the surgical and clinical outcomes. After matching, blood loss was lower in the TLDG group than in the LADG group $(94.9 \pm 65.1 \mathrm{~mL}$ vs. $145.4 \pm 116.9 \mathrm{~mL}$, respectively; $p=0.029)$. However, operative time was significantly longer in the TLDG group than in the LADG group $(211.3 \pm 30.3$ minutes vs. $168.0 \pm$ 33.8 minutes, respectively; $p<0.001$ ). The number of days before patients first passed gas was similar between groups, but patients in the TLDG group tended to consume a full liquid diet earlier than those in the LADG group ( $4.6 \pm 1.0$ days vs. $5.1 \pm 1.2$ days after surgery, respectively; $p=0.053$ ). Postoperative length of stay in the hospital was $10.6 \pm 8.2$ days in the TLDG group vs. $8.6 \pm 1.8$ days in the LADG group $(p=0.159)$. Similar numbers of patients were readmitted within 30 days (three patients [8.6\%] in the TLDG group vs. no one in the LADG group, $p=0.239$ ). In addition, patients requested similar number of additional injections for pain $(2.4 \pm 2.4$ times in the TLDG group vs. $3.3 \pm 2.8$ times in the LADG group; $p=0.164)$.

Overall, 15 patients (42.9\%) in the TLDG group had a fever vs. seven patients (20.0\%) in the LADG group ( $p=0.039)$. Change in hemoglobin was similar between groups $(2.5 \pm 1.3 \mathrm{~g} / \mathrm{dL}$ for the TLDG group vs. $2.6 \pm 1.2 \mathrm{~g} / \mathrm{dL}$ for the LADG group; $p=0.796$ ).
Mean WBC counts on postoperative days 3 to 6 were also similar (7,883.5 $\pm 2,513.6$ cells/nL for the TLDG group vs. 7,371.9 $\pm 2,059.6$ cells/nL for the LADG group; $p=0.355$ ). However, mean CRP on postoperative days 3 to 6 was greater in the TLDG group than in the LADG group $(11.4 \pm 5.7 \mathrm{mg} / \mathrm{dL}$ vs. $7.0 \pm 5.0 \mathrm{mg} / \mathrm{dL}$, respectively; $p=0.001$.

Patients had similar CD classifications. More patients in the TLDG group had major complications ( $8.6 \%$ of the TLDG group vs. $0 \%$ of the LADG group), but this difference was not significant $(p=0.239)$.

\section{Anastomotic complications}

Table 4 shows data on anastomotic complications. After matching, a greater proportion of patients in TLDG group had anastomotic complications than patients in the LADG group $(14.3 \%$ vs. $0 \%$, respectively; $p=0.054$ ). In the TLDG group, one patient had delayed gastric emptying, one had an anastomotic stricture, one had anastomotic leakage, and two had an intraabdominal abscess.

\section{DISCUSSION}

Many surgeons prefer Billroth I anastomosis to other reconstruction methods because of its physiologic advantages, such as preserved duodenal passage and reduced postoperative incidence of cholecystitis and cholelithiasis [15,16]. Furthermore, multiple anastomoses may be burdensome for surgeons, possibly leading to a longer operative time and increased risk for postoperative anastomotic leakage. For these reasons, we performed Billroth I anastomosis during TLDG, as well as during LADG, by utilizing modified delta-shaped anastomosis [19]. This procedure involves removing all staple lines used in duodenal division by adding stapling to the delta-shaped anastomosis. Studies have reported that this procedure is safe, but few studies have compared the outcomes of LADG with Billroth I anastomosis performed with a circular stapler to those of TLDG with modified delta-shaped 
anastomosis [22,23]. Therefore, we compared the methods to confirm feasibility and safety.

We observed older age, higher ASA PS classification, and higher incidence of hypertension in the TLDG group; however, these findings may have been due to the retrospective nature of this study without variable control. The higher incidence of underlying disease in the TLDG group may also be explained by the same reasons. To overcome these limitations, we performed propensity score matching with nearest neighbor matching; however, this may have been insufficient to statistically compare our groups. Since 2016, laparoscopic distal gastrectomy has been performed to treat patients with advanced gastric cancer, which may explain why tumor size was larger in the TLDG group; nevertheless, groups were similar in terms of $\mathrm{T}$ stage and final stage.

A number of studies have reported a tendency of shorter operation time in TLDG compared with LADG by 10 to 50 minutes, due to lack of the process of creation and closure of the minilaparotomy. However, in our study, the operation time for TLDG was longer (211.3 minutes vs. 168.0 minutes, respectively); this is probably because of insufficient proficiency in anastomotic techniques. LADG, on the other hand, has been practiced for many years by the same surgeons, and the anastomosis is therefore more easily and quickly performed. However, the mean operative time of TLDG was similar to those reported by previous studies (range, 115.6-298.0 minutes) [22,23]. Patients in the TLDG group had significantly less intraoperative bleeding than those in the LADG group (94.9 $\mathrm{mL}$ vs. $145.4 \mathrm{~mL}$, respectively), and other studies have reported similar results (range, 21.2-200.0 mL). However, changes in hemoglobin levels were similar between groups [22,24-26]. All patients received patient-controlled analgesia, and any additional injections were recorded to compare postoperative pain between groups. We hypothesized that patients in the TLDG group would experience less pain due to the lack of minilaparotomy, but these patients received a mean of 2.4 injections and those in the LADG group received 3.3 injections; this difference was not significant.

To determine differences in postoperative inflammation between groups, we recorded the number of patients who developed fever and calculated the mean WBC counts and CRP values. We postulated that the postoperative inflammatory response would be affected because TLDG is a less-invasive procedure and requires a smaller incision than LADG. Contrary to this notion, significantly more patients in the TLDG group had postoperative fever, and mean CRP from postoperative days 3 to 6 was also statistically higher in this group; however, mean WBC counts from postoperative days 3 to 6 were similar. Anastomotic complications may have affected these inflammatory changes, and the effects of atelectasis due to longer operative time cannot be overlooked.

Although the incidence rates of major complications were not significantly different between groups, approximately twice as many patients in the TLDG group experienced complications. This is probably due to the learning curve for this procedure, but differences in age and underlying diseases between groups may have had an effect. Nonetheless, compared to the rates of other published studies (range, 1.1\%-8.0\%), the rate of major complications in our study is not higher [26]. Additional studies with greater numbers of patients are needed to accurately evaluate this difference. In our study, one patient in the TLDG group had a grade IV complication and one patient had a grade $\mathrm{V}$ complication. The grade IV complication occurred in a 64-year-old male patient with hypertension, diabetes mellitus, obstructive coronary artery disease, atrial fibrillation, chronic kidney disease, and chronic hepatitis. He developed acute kidney injury due to chronic kidney disease, which required intermittent hemodialysis. One patient died suddenly due to a clinical course with similarities to intraabdominal bleeding; she was 56-year-old and had hypertension, diabetes mellitus, and breast cancer.

Anastomotic complications in the TLDG group included one case of delayed gastric emptying, one case of anastomotic stricture, one case of anastomotic leakage, and two cases of intraabdominal abscess. In the LADG group, one patient developed an anastomotic stricture and one developed intraabdominal abscess. Although the incidence rates of anastomotic complications were statistically similar, significantly more complications developed in the TLDG group, and this difference was even greater after propensity score matching. These complications may have developed because creation of a modified delta-shaped anastomosis with an even shape is more difficult to achieve with linear staples instead of a circular stapler; therefore, the learning curve for this procedure should also be taken into consideration. However, our results are similar to those of other studies. Delayed gastric emptying after TLDG is an anastomosis-related complication that requires caution. One patient in our study developed this complication, and our rate is comparable to that of other studies (range, 0\%-3.3\%). Therefore, this complication may not have a substantial impact on short-term outcomes. However, this assumption is based on the result of a small number of patients, and therefore future studies should enroll a greater number of patients to validate our results. Based on the results of this study, caution must be taken to lower the incidence of anastomosis-related complications in patients who undergo modified delta-shaped anastomosis, particularly among patients being treated by surgeons who are learning to perform this type of anastomosis [24-29].

The heterogeneity of the patient groups may have affected the results, and this is a limitation of this retrospective study. This limitation may erroneously indicate that TLDG is not feasible. Multicenter, randomized clinical trials are needed to confirm the results of this analysis. Furthermore, the possible effects of the learning curve for TLDG are difficult to rule out. This may 
have also negatively affected our interpretation of the safety and feasibility of TLDG; therefore, additional studies that analyze the effects of the learning curve are needed. Lastly, we compared the outcomes of LADG with TLDG performed with only Billroth I anastomosis. However, to confirm the safety and feasibility of TLDG with Billroth I anastomosis, additional studies are needed to analyze the outcomes of TLDG with Billroth II and Roux-en$\mathrm{Y}$ anastomosis.

In our early experience, TLDG is a relatively safe and feasible procedure. However, a longer operative time is required compared to that of conventional LADG, and surgeons must watch out for anastomosis-related complications.

\section{NOTES}

\section{Ethical statements}

This study was approved by the Institutional Review Board of Inje University Busan Paik Hosipital with a waiver of informed consent (IRB No. 20-0122).

\section{Authors' contributions}

Conceptualization: IL

Data curation: HJB, SHS, SHK

Formal analysis: SHS

Investigation: IL, MSA

Methodology: KHK, SHO

Project administration: SHO, YHP, SHS

Writing-original draft: IL

Writing-review \& editing: IL, KHK

All authors read and approved the final manuscript.

\section{Conflict of interest}

All authors have no conflicts of interest to declare.

\section{ORCID}

Inhyuck Lee, https://orcid.org/0000-0001-9261-7777

Kwang Hee Kim, https://orcid.org/0000-0003-2013-0788

Sang Hyuk Seo, https://orcid.org/0000-0002-7264-1339

Min Sung An, https://orcid.org/0000-0002-9210-9147

HyungJoo Baik, https://orcid.org/0000-0001-8359-5334

Yo Han Park, https://orcid.org/0000-0002-2242-0968

Sang Hyun Kang, https://orcid.org/0000-0002-8518-1941

Sang Hoon Oh, https://orcid.org/0000-0002-1290-7596

\section{REFERENCES}

1. Bray F, Ferlay J, Soerjomataram I, Siegel RL, Torre LA, Jemal A. Global cancer statistics 2018: GLOBOCAN estimates of incidence and mortality worldwide for 36 cancers in 185 countries. CA Cancer J Clin 2018;68:394-424.

2. Hong S, Won YJ, Park YR, et al. Cancer statistics in Korea: incidence, mortality, survival, and prevalence in 2017. Cancer Res Treat 2020;52: 335-350.

3. Kang KJ, Lee JH. Characteristics of gastric cancer in Korea with an emphasis on the increase of the early gastric cancer (EGC). J Korean Med Assoc 2010;53:283-289.

4. Hamashima C; Systematic Review Group and Guideline Development Group for Gastric Cancer Screening Guidelines. Update version of the Japanese Guidelines for Gastric Cancer Screening. Jpn J Clin Oncol 2018;48:673-683.

5. Shiroshita $\mathrm{H}$, Inomata $\mathrm{M}, \mathrm{Bandoh} \mathrm{T}$, et al. Endoscopic surgery in Japan: The 13th national survey (2014-2015) by the Japan Society for Endoscopic Surgery. Asian J Endosc Surg 2019;12:7-18.

6. Kim HH, Hyung WJ, Cho GS, et al. Morbidity and mortality of laparoscopic gastrectomy versus open gastrectomy for gastric cancer: an interim report: a phase III multicenter, prospective, randomized trial (KLASS Trial). Ann Surg 2010;251:417-420.

7. Han HS, Kim YW, Yi NJ, Fleischer GD. Laparoscopy-assisted D2 subtotal gastrectomy in early gastric cancer. Surg Laparosc Endosc Percutan Tech 2003;13:361-365.

8. Song KY, Kim SN, Park CH. Laparoscopy-assisted distal gastrectomy with D2 lymph node dissection for gastric cancer: technical and oncologic aspects. Surg Endosc 2008;22:655-659.

9. Bonenkamp JJ, Songun I, Hermans J, et al. Randomised comparison of morbidity after D1 and D2 dissection for gastric cancer in 996 Dutch patients. Lancet 1995;345:745-748.

10. Kitano S, Iso Y, Moriyama M, Sugimachi K. Laparoscopy-assisted Billroth I gastrectomy. Surg Laparosc Endosc 1994;4:146-148.

11. Ikeda O, Sakaguchi Y, Aoki Y, et al. Advantages of totally laparoscopic distal gastrectomy over laparoscopically assisted distal gastrectomy for gastric cancer. Surg Endosc 2009;23:2374-2379.

12. Guzman EA, Pigazzi A, Lee B, et al. Totally laparoscopic gastric resection with extended lymphadenectomy for gastric adenocarcinoma. Ann Surg Oncol 2009;16:2218-2223.

13. Huscher CG, Mingoli A, Sgarzini G, et al. Totally laparoscopic total and subtotal gastrectomy with extended lymph node dissection for early and advanced gastric cancer: early and long-term results of a 100-patient series. Am J Surg 2007;194:839-844.

14. Kanaya S, Gomi T, Momoi H, et al. Delta-shaped anastomosis in totally laparoscopic Billroth I gastrectomy: new technique of intraabdominal gastroduodenostomy. J Am Coll Surg 2002;195:284-287.

15. Loffeld RJ. Prevalence of upper abdominal complaints in patients who have undergone partial gastrectomy. Can J Gastroenterol 2000; 14:681-684. 
16. Oki E, Sakaguchi Y, Ohgaki K, et al. Feasibility of delta-shaped anastomoses in totally laparoscopic distal gastrectomy. Eur Surg Res 2011; 47:205-210.

17. Japanese Gastric Cancer Association. Japanese gastric cancer treatment guidelines 2014 (ver. 4). Gastric Cancer 2017;20:1-19.

18. Huang C, Lin M, Chen Q, et al. A modified delta-shaped gastroduodenostomy in totally laparoscopic distal gastrectomy for gastric cancer: a safe and feasible technique. PLoS One 2014;9:e102736.

19. Washington K. 7th edition of the AJCC cancer staging manual: stomach. Ann Surg Oncol 2010;17:3077-3079.

20. Daabiss M. American Society of Anaesthesiologists physical status classification. Indian J Anaesth 2011;55:111-115.

21. Dindo D, Demartines N, Clavien PA. Classification of surgical complications: a new proposal with evaluation in a cohort of 6336 patients and results of a survey. Ann Surg 2004;240:205-213.

22. Jin HE, Kim MS, Lee CM, et al. Meta-analysis and systematic review on laparoscopic-assisted distal gastrectomy (LADG) and totally laparoscopic distal gastrectomy (TLDG) for gastric cancer: preliminary study for a multicenter prospective KLASS07 trial. Eur J Surg Oncol 2019;45:2231-2240.

23. Gao J, Li P, Li QG, Chen J, Wang DR, Tang D. Comparison between totally laparoscopic and laparoscopically assisted distal gastrectomy for gastric cancer with a short follow-up: a meta-analysis. J Laparoendosc Adv Surg Tech A 2013;23:693-697.

24. Zhang B, Tu JC, Fang J, Zhou L, Liu YL. Comparison of early-term effects between totally laparoscopic distal gastrectomy with deltashaped anastomosis and conventional laparoscopic-assisted distal gastrectomy: a retrospective study. Int J Clin Exp Med 2015;8:99679972.

25. Kinoshita T, Shibasaki H, Oshiro T, Ooshiro M, Okazumi S, Katoh R. Comparison of laparoscopy-assisted and total laparoscopic Billroth-I gastrectomy for gastric cancer: a report of short-term outcomes. Surg Endosc 2011;25:1395-1401.

26. Kim BS, Yook JH, Choi YB, et al. Comparison of early outcomes of intracorporeal and extracorporeal gastroduodenostomy after laparoscopic distal gastrectomy for gastric cancer. J Laparoendosc Adv Surg Tech A 2011;21:387-391.

27. Jeong O, Jung MR, Park YK, Ryu SY. Safety and feasibility during the initial learning process of intracorporeal Billroth I (delta-shaped) anastomosis for laparoscopic distal gastrectomy. Surg Endosc 2015;29: 1522-1529.

28. Kim DG, Choi YY, An JY, et al. Comparing the short-term outcomes of totally intracorporeal gastroduodenostomy with extracorporeal gastroduodenostomy after laparoscopic distal gastrectomy for gastric cancer: a single surgeon's experience and a rapid systematic review with meta-analysis. Surg Endosc 2013;27:3153-3161.

29. Kim JJ, Song KY, Chin HM, et al. Totally laparoscopic gastrectomy with various types of intracorporeal anastomosis using laparoscopic linear staplers: preliminary experience. Surg Endosc 2008;22:436-442. 